\title{
O sentido de vida e o estresse do professorado: um estudo correlacional
}

\author{
Joilson Pereira da Silva ${ }^{\mathrm{I}, 1}$, Bruno Figueiredo Damásio ${ }^{\mathrm{II}, 2}$ e Suéllen Alencar Melo ${ }^{\mathrm{III}, 3}$ \\ I Universidade Federal de Sergipe \\ II Universidade Federal do Rio Grande do Sul \\ III Universidade Estadual da Paraíba
}

\begin{abstract}
O presente estudo teve como principal objetivo realizar um levantamento acerca dos índices de estresse percebido entre professores do Ensino Fundamental e do Ensino Médio da cidade de Campina Grande, PB, além de analisar como o estresse percebido correlaciona-se com os índices de sentido de vida. A amostra foi composta por 517 professores escolares das redes pública e particular, de ambos os sexos. Os resultados apontam que o índice de estresse percebido é relativamente alto, entretanto, é amplamente mediado pelos índices de sentido de vida. Conclui-se que a realização existencial é um aspecto que proporciona uma melhor adaptação ao cotidiano potencialmente estressor ao modificar a percepção do evento ou modificando as estratégias de enfrentamento, potencializando a saúde mental desses profissionais.
\end{abstract}

Palavras-chave: Estresse, Professores, Sentido de vida.

The meaning of life and the stress in professorship: a correlational study

The present work aimed to carry out a survey on the stress levels perceived by preliminary and high school teachers from the city of Campina Grande, PB, as well as analyzing how the perceived stress of these teachers is related to the rate of sense of life gathered. The sample was composed by 517 teachers from public and private schools from both genders. The results show that the level of perceived stress is relatively high. However, it's widely mediated by the professorship's meaning of life. The conclusion was that existential realization is an aspect that provides a better adaptation to the potentially stressful routine by changing the perception of the event or modifying the coping strategies, increasing these professionals' mental health.

Keywords: Stress, Teachers, Meaning of life.

\section{Introdução}

$\mathrm{O}_{\mathrm{r}}$ estresse nos dias de hoje é um problema que faz parte do cotidiano de grande parte da população mundial. Nas últimas duas décadas essa problemática cresceu tanto que o estresse pode ser considerado, hoje em dia, como um problema de saúde pública (Lima, 2005). No âmbito ocupacional o estresse vem sendo responsável por grandes aumentos nos gastos trabalhistas no Brasil, incluindo nessa soma despesas com tratamento médico, licença de trabalho, aposentadoria por invalidez e, é claro, queda na produtividade individual.

O local de trabalho é provavelmente o ambiente no qual o estresse manifesta-se com maior frequência, sendo um companheiro diário de trabalhadores que muitas vezes estão inseridos em situações completamente adversas ao que se espera para uma boa qualidade de vida no trabalho.

1 Docente da Universidade Federal de Sergipe. Doutor pela Universidade Complutense de Madrid.

2 Psicólogo pela Universidade Estadual da Paraíba. Mestrando pela Universidade Federal do Rio Grande do Sul.

3 Pesquisadora. Psicóloga clínica formada pela Universidade Estadual da Paraíba. 
Quando se pensa no contexto escolar, que é o foco deste estudo, ele parece ser o ambiente estressor por excelência. Tanto é que a docência é considerada atualmente como uma das profissões mais estressantes (Dejours, 1988; Garcia-Villamisar \& Guinjoan, 2003; Meleiro, 2006; Silva, 2006). E, na verdade, motivos não faltam para tal. A docência no Brasil está envolta por inúmeros fatores que contribuem para a não satisfação do professorado. Estressores administrativos (baixos salários, excessiva carga horária, perspectiva duvidosa de crescimento profissional, reduzida participação nas decisões da escola) somados aos fatores ergonômicos e sociais (má iluminação, ruídos excessivos, excesso de alunos por sala de aula, drogas, diversos tipos de violência, relacionamentos interpessoais conflituosos entre equipe profissional, pais e alunos), além de dificuldades teórico-metodológicas para lidar com problemas de aprendizagem e com crianças com necessidades especiais, entre outros, podem desencadear nos professores altos índices de estresse (Lapo \& Bueno, 2003; Meleiro, 2006; Nunes Sobrinho, 2006).

Para Kyriacou (2003), as causas do estresse nos professores podem variar de país para país. Porém, ainda não há nenhum informe concluindo que os professores estão contentes com seus trabalhos e que experienciam cotidianamente pouca preocupação. Para a autora, o estresse docente é caracterizado pelas "experiências de um professor com emoções desagradáveis, como a tensão, a frustração, a ansiedade, o cansaço e a depressão" (p. 43), podendo gerar sentimentos de desânimo e insatisfação com a docência.

Analisando essa perspectiva, Codo (citado por Delcor et al., 2004), na década de 90, destacou que $26 \%$ dos professores brasileiros apresentavam um nível de exaustão emocional considerado perigoso a sua saúde mental. Outra investigação, desenvolvida por Gasparini, Barreto e Assunção (2005), demonstrou que 16.556 atendimentos a servidores da área de educação foram realizados entre os meses de maio de 2001 a abril de 2002 na Gerência de Saúde do Servidor e Perícia Médica (GSPM) de Belo Horizonte. Desses, 84,2\% foram dirigidos a professores, resultando em afastamentos temporários em $92 \%$ dos casos. Lapo e Bueno (2003), por sua vez, relevaram que no período de 1990 a 1995, houve em São Paulo a exoneração de 5.390 professores efetivos que, na época, representavam 6,6\% do total de docentes do Estado.

Devido principalmente às péssimas condições de trabalho às quais os professores do Ensino Fundamental e Médio estão submetidos, a docência foi considerada por Dejours (1988) como uma profissão de sofrimento.

Essa perspectiva negativa da docência vem sendo amplamente investigada pelos pesquisadores nacionais, entretanto, é importante salientar que, mesmo mediante as mesmas situações externas e objetivas das más condições de trabalho, os professores diferem radicalmente na forma como percebem esse cotidiano aversivo, como demonstra os índices obtidos nas pesquisas citadas acima (se $26 \%$ apresentam um elevado índice de exaustão emocional, $74 \%$ não apresentam. Se 6,6\% dos professores abandonaram a docência, 93,4\% persistiram).

As diferentes reações que os sujeitos apresentam frente a um mesmo cotidiano potencialmente estressor é oriunda de vários fatores, como pré-disposição genética (favorecendo a maior ou menor excitabilidade orgânica), percepção acerca da gravidade do evento e a possibilidade de utilização de recursos psicossociais (que compõem, em parte, a vulnerabilidade pessoal).

Segundo Margis, Picon, Cosner e Silveira (2003), as respostas cognitivas que os indivíduos dão aos estressores são bastante pessoais e parte da simbolização que é feita sobre o evento como relevante, agradável, aterrorizante, entre outras. Assim, a problemática do estresse perpassa uma perspectiva psicológica, de maneira que a análise individual realizada por um professor acerca da situação experienciada é um fator imprescindível para compreender o estresse percebido. 
Uma vez que o estresse docente repercute de maneira particular para cada professor, é de fundamental importância que haja uma rigorosa análise sobre quais os atributos interiores presentes na vida da maioria dos professores que fazem com que eles, mesmo diante das péssimas situações contextuais, permaneçam saudáveis e ainda satisfeitos com seu emprego.

Nas palavras de Yunes (2006), "a ciência psicológica tem 'esquecido' ou negligenciado a sua mais importante missão: a de construir uma visão de ser humano com ênfase em aspectos 'virtuosos'” (p. 46). Assim, foi realizada uma vasta análise acerca de como certos recursos psicossociais e atributos interiores correlacionam-se com o estresse percebido dos professores, fortalecendo as estratégias de enfrentamento ou modificando a percepção em relação ao evento potencialmente estressor.

O presente artigo (que é uma pequena parcela de um estudo mais amplo) traz a tona uma abordagem teórica e empírica acerca de como o estresse percebido está amplamente correlacionado com um aspecto inerente à natureza humana: a realização existencial. Para esta análise, utilizaremos da perspectiva teórica da logoterapia e análise existencial, fundada por Viktor Frankl, demonstrando como a vontade de sentido (termo que expressa necessidade da busca de auto-realização) é um forte atributo para a qualidade de vida das pessoas.

\section{Logoterapia e análise existencial: uma breve análise teórica}

A logoterapia e análise existencial é uma escola de psicoterapia criada por Viktor Frankl (médico psiquiatra e neurologista austríaco) em meados da década de 20. Considerada a terceira escola vienense de psicoterapia, a logoterapia e análise existencial funda uma teoria voltada para o sentido da existência humana, partindo da premissa de que a principal ambição do homem é a busca por um sentido existencial. Esse fundamento básico da logoterapia contrapôs as duas perspectivas psicoterápicas até então vigentes - a psicanálise, proposta por Sigmund Freud, e a psicologia individual, proposta por Adolf Adler -, que teorizaram acerca do princípio do prazer e do complexo de inferioridade aliado à vontade de poder, respectivamente.

Para Frankl, o prazer ou o poder em si não seria a meta principal do homem, mas a consequência da realização de suas aspirações. O ser humano seria "um ente empenhado na busca de sentido" (Frankl, 1978, p. 11) e mediante isso poderia atingir sua felicidade e plenitude.

O sentido existencial, de acordo com os pressupostos filosóficos e antropológicos da logoterapia, pode ser encontrado através de três categorias de valor que possibilitam ao homem realizar-se enquanto ser-no-mundo (Frankl, 1978, 1992). Esses valores são elementos comuns entre as pessoas que encontraram suas respostas (Rodríguez, 2005). A primeira categoria de valor, a qual será focada mais diretamente devido à natureza desta investigação, diz respeito à realização de uma atividade ou um trabalho significativo, intitulada de valores criativos. Essa categoria de valor proporciona ao sujeito a possibilidade de sentir-se socialmente útil e mais que isso, a realização existencial por meio de um trabalho que tenha sentido para si, independente da profissão.

A segunda categoria de valores é intitulada de valores vivenciais. Esses dizem respeito a contemplar o que é belo na vida, aproveitar momentos de êxtase, plena satisfação, constituindo o enriquecimento pessoal através das vivências. Diz respeito também a amar algo ou alguém. Os valores vivenciais podem ser analisados, por exemplo, em um professor dedicado que vê a formatura de seus alunos, o alpinista que chega ao cume da montanha, o pai que vê o nascimento de um filho esperado, o resultado positivo de um emprego desejado. Em suma, momentos de conquistas pessoais que fazem a vida valer a pena e ter sentido. 
A terceira categoria são os valores atitudinais. Esse tipo de valor encontra-se diante dos sofrimentos inevitáveis ou de fatalidades trágicas. Diz respeito a que postura humana é tomada frente às adversidades: desespero ou crescimento existencial.

Remetendo à realização existencial mediante os valores criativos, pode-se dizer que um trabalho realizado com sentido pode ser um meio fortemente capaz de realizar existencialmente o ser. Como afirma Bohoslavsky (citado por Lapo \& Bueno, 2003), quando o indivíduo pensa em uma profissão, ele pensa em algo que se relaciona com sua realização pessoal, sua felicidade, alegria de viver etc., como quer que isso seja entendido. Para a logoterapia e análise existencial, a proposta de Bohoslavsky é entendida como o trabalho sendo um meio fundamental para a realização de sentido existencial.

Se a profissão é significativa na realização existencial do professor, o trabalho será mais facilmente considerado como prazeroso, significativo e satisfatório, apesar das adversidades. Em contrapartida, se através de uma análise pessoal o professor percebe que a docência não é algo satisfatório para si em nenhum aspecto, esses sujeitos estarão no maior grupo de risco para enfrentar problemas com o estresse no trabalho, uma vez que não há satisfação com as condições de trabalho nem tampouco o trabalho é importante para seus objetivos de vida. Logo, de acordo com o sentido que o trabalho tenha na vida do professor, haverá distintas respostas aos aspectos potencialmente estressores no cotidiano.

Para Acevedo (1999), a realização existencial ajuda as pessoas (neste caso, os profesores) a enfrentarem de forma mais satisfatória as adversidades cotidianas auxiliando-os a responder e a reagir com mais eficácia aos problemas diários, encontrando sentido para as situações cotidianas. Mascaro e Rosen (2006), por exemplo, demonstraram que o índice de distresse é diminuído através da percepção de um sentido para a situação estressante, de maneira que: 1) quando não há uma realização de sentido diante da situação potencialmente estressora, o evento culmina no distresse, repercutindo de forma negativa para a saúde mental; 2) quando há a percepção de sentido, a visão sobre o evento estressor modifica-se e passa a ser considerado como um desafio positivo e inerente à vida, que impulsiona a realização existencial, repercutindo de forma positiva na saúde mental.

Além disso, baixos índices de sentido de vida repercutem em percepção da vida de maneira negativa, o que traz à tona com maior frequência sentimentos de aborrecimento e apatia. A concretização de sentido, por sua vez, repercute de maneira positiva na vida das pessoas na medida em que os valores que mediam a realização existencial baseiam-se em atitudes de amor, esperança, otimismo, felicidade, auto-transcendência, que são características imprescindíveis à resiliência (capacidade de superação de problemas) (Lieber, Epelbaum \& Epelbaum, 2007).

Clarificando essa correlação, ao analisar o sentido de vida em jovens, Halama (2000) demonstrou que as estratégias de enfrentamento de problemas (coping) variam radicalmente de acordo com o índice de realização existencial. Os dados da pesquisa demonstram que pessoas que apresentaram os valores voltados para si (frustração da vontade de sentido, uma vez que a realização existencial acontece mediante a auto-transcendência, no abrir-se para o mundo) utilizaram estratégias de violência, enquanto os que apresentaram um maior índice de sentido de vida utilizam de estratégias de coping mais adequadas.

Outro estudo, realizado por Hutchinson (2005), demonstra que há significantes diferenças entre pessoas que apresentam baixo sentido de vida comparadas a indivíduos com índice elevado. A forte associação entre realização existencial e bem-estar dá-se devido ao fato de que pessoas com maiores índices de sentido de vida geralmente são mais responsáveis, direcionadas a objetivos específicos, melhor ajustadas socialmente e melhor orientadas no que diz respeito a relacionamentos interpessoais, demonstrando que esse aspecto da natureza humana repercute fortemente no bem-estar psicológico, dando importantes saltos positivos na 
qualidade de vida das pessoas (Frankl, 1978, 1992, 2001; Halama, 2000; Lieber et al., 2007; Mascaro \& Rosen, 2006; Vanek, 2005).

Analisando a questão do sentido de vida dos professores e, mais precisamente, o sentido da docência em suas vidas, pretende-se trazer a tona algumas evidências teóricas e empíricas acerca de como um alto índice de sentido de vida é capaz de apaziguar os índices de estresse cotidiano, ajudando na percepção e nas tomadas de atitude mediante situações controversas no dia-a-dia.

\section{Método}

\section{Amostra}

A amostra desta investigação foi constituída por 517 professores do Ensino Fundamental e Médio da cidade de Campina Grande, PB, escolhidos por conveniência (disponibilidade de acesso) em 57 escolas públicas e particulares, com idade média de 36,6 anos (desvio padrão=10,34; mínimo: 16; máximo: 65).

Mediante consentimento prévio da diretoria da escola, foram marcados horários em dias úteis da semana para a realização da coleta de dados. Como critério de inclusão, fez-se necessário que os professores fossem efetivos em seus cargos. Participaram da coleta apenas os profissionais que, por livre e espontânea vontade, disponibilizaram-se para tanto. Do total da amostra, 34,11\% dos professores são homens e 65,89\% são mulheres.

Durante a coleta de dados, a amostra foi dividida de maneira semi-igualitária para o Ensino Fundamental I (168 professores, sendo 4 homens e 164 mulheres), Ensino Fundamental II (173 professores, sendo 85 homens e 88 mulheres) e Ensino Médio (176 professores, sendo 85 homens e 91 mulheres). A alta incidência do número de mulheres na amostra dá-se devido ao fato de que a prevalência de professores do sexo masculino no Ensino Fundamental I é bastante escassa.

A amostra total desta investigação corresponde, segundo informações colhidas nas secretarias de educação municipal e estadual e secretaria das escolas particulares, a cerca de $12 \%$ da totalidade de professores do município.

\section{Instrumentos}

Para a coleta de dados foram utilizados três instrumentos: o primeiro é uma adaptação e validação da escala de estresse percebido (EEP-14) de Cohen, Karmack e Mermelsteinm (1983). Trata-se de um auto-informe do tipo Likert que consta de 14 itens relativos ao estresse e cuja pontuação oscila entre 1 (nunca) e 5 (sempre). A escala foi adaptada e validada para a amostra de professores no Brasil pelos autores do presente artigo (trabalho ainda não publicado), mantendo bons índices psicométricos, como serão descritos adiante.

O segundo instrumento utilizado diz respeito a uma adaptação do instrumento de sentido de vida (PIL-Test), de Crumbauch e Maholick (1974), baseado na perspectiva humanística-existencial da teoria de Viktor Frankl. O questionário possui escala tipo Likert e varia de 1 (discordo totalmente) a 7 (concordo totalmente). A presente pesquisa utilizou uma adaptação que reduziu o instrumento original de 20 para 12 itens, mantendo bons índices psicométricos, e foi intitulada de PIL-Test-12. 
Por fim, o terceiro instrumento foi o questionário de informações complementares (QIC), incluindo dados sócio-demográficos tais como: idade, gênero, estado civil, grau de formação, série para a qual o professor leciona, renda mensal, além de questões referentes a satisfação no trabalho e violência percebida.

\section{Procedimento}

O questionário foi administrado aos professores nas instituições em que lecionavam, com aplicação durando em média 25 minutos. As análises dos dados foram realizadas através do programa estatístico para as ciências sociais (Statistical Package for the Social Sciences, SPSS-15). Por meio desse programa foi efetuada uma análise fatorial tipo PAF (principais eixos fatoriais, em português) reduzindo o número de itens dos questionários a fatores, como será visto posteriormente.

\section{Resultados e discussões}

\section{Análise da escala de estresse percebido}

A escala de estresse percebido apresentou índices de $\mathrm{KMO}$ e teste de esfericidade de Bartlett bastante significativos ( $\mathrm{KMO}=0,86$; teste de esfericidade de Bartlett $\left.x^{2}=1320,883\right)$, atestando a possibilidade de realização de análise fatorial. Para calcular o índice de estresse dos professores foi utilizada a análise fatorial tipo PAF, com rotação varimax, no intuito de encontrar os principais fatores constituintes da EEP-14.

Em consonância com a escala original, foram encontrados dois fatores significantes, ambos com eigenvalues $\geq 1$ e medidas de confiabilidade interna (alfa de Cronbach) $\geq 0,7$.

\section{Quadro 1. Estatísticas descritivas da EEP-14}

\begin{tabular}{|l|l|l|}
\hline \multirow{2}{*}{ Escala de estresse percebido (N=517) } & Fator I & Fator II \\
\cline { 2 - 3 } & Estresse percebido & Má administração do estresse \\
\hline Média Obtida & 16,4 & 17,5 \\
\hline Moda & 17 & 20 \\
\hline Desvio-Padrão & 3,4 & 4,0 \\
\hline Mínimo obtido & 8 & 8 \\
\hline Máximo obtido & 29 & 31 \\
\hline Valor máximo possível ${ }^{4}$ & 30 & 35 \\
\hline Alfa de Cronbach & 0,71 & 0,73 \\
\hline
\end{tabular}

O primeiro fator da escala (estresse percebido) apresentou índice de confiabilidade interna (alfa de Cronbach) igual a 0,71. Ele é composto por seis itens com carga fatorial $\geq 0,30$ (valor mínimo considerado para inclusão dos itens no fator) e avalia o nível de estresse cotidiano dos professores. Através do calculo da média obtida nesse fator, pôde-se perceber que

4 O valor máximo possível se dá pelo cálculo entre os pontos da escala (valores na escala Likert), multiplicado pelo número de itens que constitui cada fator. 
os professores campinenses apresentam um índice de estresse percebido considerado relativamente elevado, atingindo média de 16,4 pontos, dos 30 possíveis. Do total da amostra, $39,3 \%$ dos professores apresentaram índices de estresse baixo ou regular, enquanto $60,7 \%$ apresentaram resultados razoavelmente elevados ou altos.

O segundo fator da escala (má-administração do estresse) apresentou coeficiente de confiabilidade interna (alfa de Cronbach) igual a 0,73. O fator é composto por sete itens (com carga fatorial $\geq 0,30$ ) e diz respeito à forma como o sujeito administra os acontecimentos cotidianos. Através dos resultados obtidos, pôde-se comprovar que há certa dificuldade de adaptarem-se às exigências diárias, uma vez que a média obtida $(17,5)$ apresentou-se no patamar mediano do valor máximo possível, que seriam 35 pontos.

Ainda acerca do EEP-14, ambos os fatores dessa escala apresentaram correlações significativas com alguns dados do QIC. O estresse percebido apresentou correlação com a dependência financeira $(r=0,09$, com significância $\mathrm{p}<0,01)$ e com a violência no trabalho $(\mathrm{r}=0,17$, com significância $\mathrm{p}<0,05)$.

A dependência financeira parece ser um aspecto potencialmente estressor, na medida em que os professores sentem-se incapazes de manusear a sua vida de forma autônoma e suprir determinadas necessidades pessoais. É provavelmente por isso que questões como quantidade de trabalho (postos de trabalho e expedientes exercidos) não apresentaram correlações significativas com o estresse percebido, dado que a dependência financeira está fortemente correlacionada com a quantidade de trabalho exercido $(r=-0,25$, com significância $p<0,01)$.

A violência no trabalho foi também considerada como um aspecto potencialmente estressor. A agressão, seja ela física, verbal ou moral, atesta grande falta de respeito e desvalorização do papel docente. Devido à amplitude e à importância dessa temática, ela não poderá ser aprofundada neste momento.

É importante salientar ainda que, através do teste $t$ de student, foi observado que não houve diferenças estatisticamente significativas nas médias de estresse percebido em relação a gênero, estado civil ou tipo de instituição em que o professor leciona (pública ou particular). Tampouco houve diferença significativa nas médias de estresse entre os professores do Ensino Fundamental I, Ensino Fundamental II e Ensino Médio, corroborando os resultados encontrados por Rossa (2004).

\section{Análise da escala de sentido de vida}

No que diz respeito ao PIL-Test-12, foi verificado, através da rotação varimax, que o questionário de sentido de vida apresenta também dois fatores significantes. A medida da adequação da amostra apresentou resultado bastante elevado $(\mathrm{KMO}=0,864)$. Conforme demonstrado no Quadro 2, o primeiro fator do PIL-Test-12 refere-se ao vazio existencial, enquanto o segundo fator se refere à realização existencial. 
Quadro 2. Estatísticas descritivas do PIL-Test-12

\begin{tabular}{|c|c|c|}
\hline \multirow{2}{*}{ PIL-Test-12 $(\mathrm{N}=517)$} & Fator I & Fator II \\
\hline & Vazio existencial & Realização existencial \\
\hline Média obtida & 13,3 & 39,3 \\
\hline Moda & 8 & 44 \\
\hline Desvio-padrão & 5,81 & 6,25 \\
\hline Mínimo obtido & 7 & 17 \\
\hline Máximo obtido & 41 & 49 \\
\hline Valor máximo possível & 49 & 49 \\
\hline Alfa de Cronbach & 0,75 & 0,75 \\
\hline
\end{tabular}

Utilizando a correlação de Pearson (r), foi demonstrado que há uma forte correlação negativa entre os dois fatores do PIL-Test-12 ( $\mathrm{r}=-0,64$, com significância $\mathrm{p}<0,01)$. Essa correlação parece atestar que dois estados existenciais (vazio e realização) não coexistem simultaneamente em uma mesma pessoa. Assim, a realização existencial previne que o sujeito depare-se com frustrações e vazios existenciais que, de acordo com Frankl (2001), é o fator desencadeante do que o autor intitula de neuroses ou depressões noogênicas, oriundas de um conflito existencial.

Ainda trabalhando os fatores da escala de sentido de vida, pode-se afirmar, através das médias obtidas (ver Quadro 2), que os professores da cidade de Campina Grande apresentam um índice de realização existencial bastante superior ao índice de vazio existencial.

A concretização de sentido, no caso dos professores, pode ser obtida diariamente através da docência (e se assim o for, o trabalho será visto como mais prazeroso), assim como pode, também, ser obtida através de outros meios, como a família, outra atividade prazerosa que o professor desempenhe ou por um sofrimento inevitável. Independente de qual categoria de valor o sentido esteja sendo realizado, será notável a repercussão no estresse cotidiano desses profissionais. Porém, este estudo foca-se mais diretamente no sentido da docência (valores criativos) porque, se a docência for vista como uma atividade sem sentido, ela tenderá a ser eliminada do cotidiano da vida do professor (abandono da profissão caso haja possibilidade), uma vez que as condições de trabalho são bastante desgastantes.

Se o professor acredita que a docência é um fardo, que trabalha por obrigação por ser o único meio de subsistência, não havendo possibilidade de se desvincular do cargo, ele poderá realizar sentido ainda como tendo que vivenciar um sofrimento inevitável (valores atitudinais). Entretanto, esta perspectiva parece não corroborar com os resultados obtidos, pois, do total de professores da amostra, 80,1\% dizem estar satisfeitos com o seu trabalho e apenas 19,9\% afirmam não estarem satisfeitos. Por isso, neste estudo, a docência foi tratada como um meio de realização através dos valores criativos.

Conforme aponta a logoterapia e análise existencial em seus pressupostos básicos, os valores criativos (realização de uma atividade satisfatória) são um aspecto vital amplamente capaz de aumentar os índices de sentido de vida das pessoas no geral (Frankl, 1978, 2003, 2004). No presente estudo, esse fundamento é corroborado. Estatisticamente, há uma relação fortemente significativa entre a realização existencial e a satisfação profissional $(r=0,26 \mathrm{com}$ significância $\mathrm{p}<0,01)$. É importante salientar que a completude da satisfação existencial na vida de uma pessoa engloba vários aspectos e também nunca chegará à completude total, uma vez que os valores são situacionais, isto é, dependem do momento vivido. Como muitos professores mantêm outros vínculos sociais além do trabalho (tais como família, filhos, amigos), 
provavelmente pode-se encontrar significantes relações nesse sentido, somando-se na completude da realização existencial desses profissionais.

\section{Correlação entre os instrumentos EEP-14 e Pil-Test-12}

Em relação à correlação entre as escalas de estresse percebido e sentido de vida, utilizou-se mais uma vez a correlação de Pearson, conforme apresentado no Quadro 3.

Quadro 3. Correlação de Pearson entre as escalas de estresse percebido e de sentido de vida

\begin{tabular}{|l|l|l|l|l|}
\hline \multirow{2}{*}{ EEP-14 e Pil-Test-12 } & EEP-14 \\
\cline { 4 - 5 } \multicolumn{2}{|l|}{} & Fator I & Fator II \\
\cline { 4 - 5 } Pil-Test-12 & Fator I & Vazio existencial & $0,47(* *)$ & Má-administração do estresse \\
\cline { 4 - 5 } & & & $0,47(* *)$ \\
\cline { 3 - 5 } & Fator II & Realização existencial & $-0,42(* *)$ & $-0,51(* *)$ \\
\hline
\end{tabular}

** Correlação com significância p $<0,05$

Através do Quadro 3, pode-se perceber que todos os índices de ambas as escalas correlacionam-se de maneira muito significativa. É demonstrado que quanto maior o índice de vazio existencial, maiores são os índices de estresse cotidiano e maior a percepção de que não se está conseguindo lidar com os problemas diários (má-administração do estresse).

Acerca das respostas cognitivas, o estresse percebido e a má-administração das situações cotidianas ocorrem quando as exigências (internas ou externas) são maiores que as capacidades e os recursos que a pessoa tem para enfrentá-las (Iglesias, 2003). Dessa maneira, é possível afirmar que o nível de estresse percebido, assim como a má-administração do estresse, são mediados pelo índice de vazio existencial, que seria reflexo da inexistência do recurso sentido de vida.

É importante salientar que o sentido de vida é intitulado neste estudo como recurso uma vez que maiores índices de realização existencial proporcionam melhor adaptação às situações potencialmente estressoras. Porém, esse recurso não é um recurso psicossocial, mas um recurso latente e inerente a todo ser humano.

A realização existencial, por sua vez, correlaciona-se de maneira negativa tanto com o estresse percebido, quanto com a má-administração do estresse, devido ao fato de que o sentido existencial modela as situações de enfrentamento de problemas ao modificar a percepção ou o significado de acontecimentos potencialmente estressores, repercutindo em uma melhor adaptação às situações conflituosas (Ghadirian, 1983).

Sendo assim, o sentido de vida pode ser considerado como um suporte interno à existência e, sem esse suporte, o psiquismo torna-se mais frágil, com maiores probabilidades de enfermar (Rodríguez, 2005). 


\section{Considerações Finais}

Os resultados do estudo demonstram que, no tocante às variáveis sócio-demográficas, não houve diferenças significativas em relação ao gênero, estado civil, tipo de escola (pública ou particular) e níveis de atuação dos professores (Ensino Fundamental I, Ensino Fundamental II ou Ensino Médio).

A correlação existente entre sentido de vida e estresse percebido pôde ser comprovada de maneira bastante satisfatória. Entretanto, é importante salientar que o nível de estresse percebido foi considerado relativamente alto, mesmo diante dos elevados índices de realização existencial e de satisfação com o trabalho. Diante desse fato, surgiram dois principais questionamentos: a realização existencial é capaz de eliminar totalmente o estresse percebido? E, ainda, qual a correlação existente entre satisfação profissional e trabalho estressante?

Em relação à realização existencial, faz-se necessário salientar que, mesmo em condições adversas, o ser humano é capaz de encontrar sentido nas suas vivências. Assim, a realização existencial por meio do trabalho (valores criativos) pode emergir independente das condições nas quais a docência está inserida. Corroborando essa afirmação, pode-se citar, por exemplo, relatos escritos encontrados nos questionários de professores que, ao serem questionados sobre o "porquê" da satisfação, afirmaram que estavam satisfeitos com a profissão, mas não com as condições em que era exercida.

Em outras palavras, as condições em que a docência está inserida pode, por vezes, não influir diretamente na percepção do sentido do trabalho para a vida do professor - um trabalho significativo, apesar dos pesares. Porém, tais condições parecem influenciar os índices de estresse, uma vez que, por exemplo, foram encontradas correlações entre: estresse percebido e violência sofrida na escola, estresse percebido e dependência financeira, mas não foram encontradas tais correlações com os índices de realização ou vazio existencial. Assim, teoriza-se que os índices de estresse percebido podem resultar de alguns fatores que não estejam correlacionados com a realização existencial do professor e, nessa perspectiva, a realização existencial em determinado momento pode ser incapaz de proteger o sistema psicofísico contra o estresse diante determinada situação, deixando algumas lacunas (certamente por isso, a correlação entre estresse percebido e realização existencial, apesar de alta, não é total).

Dessa maneira, mesmo levando em consideração que o sentido de vida é um fator de proteção frente ao estresse, ele parece agir como um recurso apaziguador, capaz de diminuir, mas não bloquear por completo a percepção negativa de todas as problemáticas existentes.

Em relação ao segundo questionamento, os dados apontam que há um elevado índice de satisfação no trabalho, mas, em contrapartida, há também um elevado nível de estresse percebido pelos professores. Acerca dessa aparente contradição é necessário salientar que a análise da satisfação no trabalho foi feita apenas por um único item (de respostas "sim", "não", e "por quê?"). Se for utilizada uma escala mais adequada de satisfação no trabalho é possível que os resultados apresentem alterações substanciais.

É importante salientar também que a relação existente entre trabalho estressante e satisfação profissional parece não estar clara até os dias atuais. $O$ estresse percebido, bem como outras psicopatologias ocupacionais apresentam, além das condições externas do trabalho, complexos componentes subjetivos que influenciam (ou não) o desencadeamento das síndromes.

No intuito de compreender mais profundamente a relação existente entre satisfação profissional e trabalho estressante, foi realizado um levantamento bibliográfico no banco de dados das bibliotecas virtuais Medline, Lilacs e Scielo. Porém, não foram encontrados estudos nacionais coesos que apresentassem dados significativos sobre quanto o estresse percebido está correlacionado com a satisfação no trabalho nem tampouco a direção de causalidade entre 
ambos os aspectos (o estresse percebido influencia a satisfação no trabalho ou a satisfação no trabalho influência o estresse percebido?). Para adentrar mais profundamente nesse campo de investigação, que continua em aberto, faz-se necessário avaliar também os mediadores que possam interferir nessa relação, tais quais: vínculo empregatício (fixo, temporário, autônomo), tempo de serviço prestado, idade, gênero, entre outros.

Além dos aspectos supracitados, é imprescindível relatar que a escala de estresse percebido utilizada nesta investigação não se relaciona diretamente com o ambiente ocupacional. Porém, os resultados apontam que em Campina Grande os professores estão submetidos a um nível inadequado de tensão cotidiana. Mediante as circunstâncias em que o questionário foi aplicado, pela natureza da investigação (analisar o estresse dos professores) e tendo como base a literatura atual, infere-se que grande parte desse estresse percebido seja oriundo de um cotidiano de trabalho potencialmente estressor.

Dessa maneira, mesmo havendo bons índices de satisfação no trabalho e bons índices de sentido de vida que ajudem os professores a sobressaírem-se das adversidades diárias, parece ser imprescindível que haja uma política nacional ou das próprias instituições que vise reduzir (ou, se possível, eliminar) os principais estressores inclusos no cotidiano escolar, para que o processo de proteção ao bem-estar psicológico desses profissionais seja, antes de tudo, preventivo.

Como um profissional que está submetido a más condições de trabalho tende a render menos, o estresse na docência repercute tanto no professor, no âmbito pessoal, quanto na educação, no âmbito social, de maneira que a educação passa a não cumprir de forma satisfatória os seus objetivos, que são educar e formar cidadãos, tornando-os conscientes de seus direitos e deveres, capacitá-los a desenvolver suas potencialidades pessoais e, como consequência, gerar desenvolvimento social.

Assim, é imprescindível que as pesquisas em relação ao estresse ocupacional englobem cada vez mais novos fatores, para que haja um maior conhecimento acerca de suas causas, consequências, incidência e prevalência, dando maior respaldo para uma atuação preventiva no combate às psicopatologias do trabalho em geral.

\section{Referências}

Acevedo, G. (1999). Relación entre la calidad de vida, el enfermar y la logoterapia. NOUS: Boletín de Logoterapia y Análisis Existencial, 3, 7-35.

Cohen, S., Kamarck, T. \& Mermelstein, R. (1983). A global measure of perceived stress. Journal of Health and Social Behaviour, 24 (4), 385-396.

Crumbaugh, J. H. \& Maholick, L. T. (1974). The psychometric approach to Frankl's concept of noogenic neurosis. Journal of Clinical Psychology, 20, 200-212.

Dejours, C. (1988). A loucura do trabalho: estudo de psicopatologia do trabalho. São Paulo: Cortez.

Delcor, N. S., Araújo, T. M., Reis, E. J. F. B., Porto, L. A., Carvalho, F. M., Silva, M. O., Barbalho, L. \& Andrade, J. M. (2004). Labor and health conditions of private school teachers in Vitória da Conquista, Bahia, Brazil. Cadernos de Saúde Pública, 20 (1), 187-196.

Frankl, V. E. (1978). Fundamentos antropológicos da psicoterapia. Rio de Janeiro: Zahar.

Frankl, V. E. (1992). A presença ignorada de Deus (2 ${ }^{\mathrm{a}}$ ed.). Rio de Janeiro: Vozes.

Frankl, V. E. (2001). Teoría y terapia de las neurosis (2ª ed.). Barcelona: Herder.

Frankl, V. E. (2004). Em busca de sentido (19ª ed.). Rio de Janeiro: Vozes.

Frankl, V. E (2003). Psicoterapia e sentido da vida: fundamentos da logoterapia e análise existencial (4⿳亠丷a ed.). São Paulo: Quadrante. 
Ghadirian, A. M. (1983). Human responses to life stress and suffering. Baha'I Studies Notebook, 3 (2), 50-62.

García-Villamisar, D. \& Guinjoan, T. (2003). El estrés de los profesores: actualización psicológica de um viejo problema. In D. García-Villamisar \& T. Freixas Guinjoan (Eds.), El estrés del professorado: una perspectiva internacional (pp. 19-38). Valencia: Promolibro.

Gasparini, S. M., Barreto, S. M. \& Assunção, A. A. (2005). O professor, as condições de trabalho e os efeitos sobre sua saúde. Educação e Pesquisa, 31 (2), 189-199.

Halama, P. (2000). Dimensions of life meaning as factor of coping. Studia Psychologica, 42, 339-350.

Hutchinson, A. K. (2005). Meaning in life and sense of coherence as predictors of coping among young adults. Dissertação de Mestrado, Faculdade de Humanidades, Universidade de Johannesburg, África do Sul.

Iglesias, E. B. (2003). Técnicas psicológicas para la prevención y el tratamiento del estrés. In D. García-Villamisar \& T. Freixas Guinjoan (Eds.), El estrés del professorado: una perspectiva internacional (pp. 185-200). Valencia: Promolibro.

Kyriacou, C. (2003). El estrés em la enseñanza: revisión histórica y estado actual. In D. García-Villamisar \& T. Freixas Guinjoan (Eds.), El estrés del professorado: una perspectiva internacional (pp. 39-59). Valencia: Promolibro.

Lapo, F. R. \& Bueno, B. (2003). Os Professores, desencanto com a profissão e abandono do magistério. Cadernos de Pesquisa, 118, 65-88.

Lima, F. V. (2005). Correlação entre variáveis preditoras de estresse e o nível de estresse. Dissertação de Mestrado, Faculdade de Educação Física, Universidade Católica de Brasília, Brasília.

Lieber, I. I., Epelbaum, A. \& Epelbaum, D. M. (2007). Resiliência y senectud: la movilización de la fé, la esperanza, el sentido de la vida y la espiritualidad. Boletin Electrónico da Associação de Psiquiatras Argentinos, 42.

Margis, R., Picon, P., Cosner, A. F. \& Silveira, R. O. S. (2003). Relação entre estressores, estresse e ansiedade. Revista de Psiquiatria do Rio Grande do Sul, 25 (1), 65-74.

Mascaro, N. \& Rosen, D. H. (2006). The role of existential meaning as a buffer against stress. Journal of Humanistic Psychology, 46 (2), 168-190.

Meleiro, A. M. A. S. (2006). O stress do professor. In M. E. N. Lipp (Org.), O stress do professor (pp. 11-27). Campinas: Papirus.

Nunes Sobrinho, F. P. (2006). O stress do professor do ensino fundamental: o enfoque da ergonomia. In M. E. N. Lipp (Org.), O stress do professor (pp. 81-94). Campinas: Papirus.

Rodríguez, M. (2005). Sentido de vida y salud mental. Revista Acontecimento, Instituto Emmanuel Mounier, 21 (74), 47-49.

Rossa, E. G. O. (2004). Relação entre o estresse e o burnout em professores do ensino fundamental e médio. In M. E. N. Lipp (Org.), O stress no Brasil: pesquisas avançadas (pp. 131-138). Campinas: Papirus.

Silva, M. E. P. (2006). Burnout: por que sofrem os professores? Estudos e Pesquisas em Psicologia, 6 (1), 89-98.

Vanek, M. T. L (2005). Depresión y suicidio: herencias del mundo moderno. Artigo disponível na Internet: http://www.logoforo.com/

Yunes, M. A. (2006). Psicologia positiva e resiliência: foco no indivíduo e na família. In D. D. Dell’ Aglio, S. H. Koller \& M. A. M. Yunes (Orgs.), Resiliência e psicologia positiva: interfaces do risco à proteção (pp. 46-68). São Paulo: Casa do Psicólogo.

\section{Endereço para correspondência}

joilsonp@hotmail.com, brunofd@msn.com, suellenamelo@hotmail.com 